\title{
HELICOBACTER PYLORI E A GASTRITE: um estudo retrospectivo
}

Dayane Resende MATA $^{1}$

Yuri CORDEIRO

Frederico Pinheiro de LIMA $^{3}$

Talita Lopes do Nascimento da SILVA

Tiago Lopes CESCHINI ${ }^{5}$

Charlene Correa MENDES ${ }^{6}$

Carolina Oliveira BERNARDES ${ }^{7}$

Luiz Carlos de ANDRADE ${ }^{8}$

Roberta Bessa Veloso SILVA ${ }^{9}$

Eric Batista FERREIRA ${ }^{10}$

1,2,3,4,5,6,7 Acadêmica do curso de Medicina, Universidade José do Rosário Vellano /UNIFENAS.

${ }^{8}$ Professor e médico gastroenterologista do Hospital Universitário Alzira Velano/HUAV/UNIFENAS e-mail: endoscopia.huav@unifenas.br

${ }^{9}$ Doutora em Estatística e Experimentação Agropecuária/UFLA, Universidade José do Rosário Vellano/UNIFENAS e-mail: bessaveloso@yahoo.com.br

${ }^{10}$ Doutor em Estatística e Experimentação Agropecuária/UFLA, Universidade Federal de Alfenas/UNIFAL e-mail: eric.ferreira@unifal-mg.edu.br

Recebido em: 08/07/2016 - Aprovado em: 10/09/2016 - Disponibilizado em: 18/12/2016

\section{RESUMO:}

A gastrite tem diversos fatores etiológicos e pode ser classificada de acordo com sua evolução temporal, em aguda e crônica, mecanismo patogênico, localização anatômica e características histológicas. A forma mais comum da gastrite crônica, que atinge predominantemente a região antral, tem como agente causador a bactéria HelicobacterPylori $(H$. Pylori). Essa forma de gastrite aumenta com o decorrer do tempo e pode evoluir a uma pangrastrite, em média, num tempo de 15 a 20 anos. A infecção por H. Pylori induz a inflamação persistente na mucosa gástrica com diferentes tipos de lesões, por isso tem sido associado à etiopatogenia de diversas doenças, tais como úlcera péptica, câncer gástrico, MALT (linfoma do tecido linfoide associado a mucosa) e com o linfoma não-Hodgkin gástrico. Diante disso, foi conduzido um estudo transversal de base secundária, através do levantamento de dados disponíveis em laudos patológicos de pacientes que foram submetidos as biopsias realizadas por endoscopia digestiva alta registrados no Hospital Universitário Alzira Velano, Alfenas, MG, durante o período de 2009 a 2014. Foram analisados 753 registros. Após a coleta das informações, foi aplicado o teste estatístico exato de Fisher, ao nível nominal de significância de $5 \%$.Os resultados permitem concluir que houve associação significativa entre a gastrite e gênero. Não foi observado uma associação significativa entre a gastrite e $H$. Pylori, e, também entre H. Pylorie gênero.

Palavras-chave: Infecção, Bactéria, Câncer gástrico, Gastrite, Fatores de risco.

\section{ABSTRACT:}

Gastritis has multiple etiologies and can be classified according to its evolution in acute and chronic, pathogenic mechanism, anatomical location and histological characteristics. The most common form of chronic gastritis, which predominantly affects the antral region, is the causative agent the bacteriumHelicobacter Pylori $(H$. Pylori). This form of gastritis increases with the passage of time and may lead to a pangrastrite, on average, a time of 15 to 20 years. The 
H. pylori infection induces persistent inflammation in gastric mucosa with different types of lesions, so it has been associated to the pathogenesis of several diseases such as peptic ulcer, gastric cancer, MALT (lymphoma of mucosaassociated lymphoid tissue) and gastric non-Hodgkin's lymphoma. Thus, a cross-sectional study of secondary base was conducted through survey data available in pathological records of patients who submittedt biopsies performed by endoscopy conducted at the University Hospital AlziraVelano, Alfenas - MG, during the period 2009 to 2014 . Were analyzed 753 records.After collecting the information, Fisher's exact statistical test was applied to the nominal significance level of 5\%. The results showed that there was a significant association among gastritis and gender. No significant association among $H$. pylori and gastritis, and also among $H$. pylori and gender was observed.

Keywords: Infection, Bacterium, Gastric Cancer, Gastritis, Risk factors.

\section{Introdução}

De acordo com Longoet al. (2014), a gastrite resultada inflamação da mucosa gástrica e não deve ser confundida com eritema e/ou dispepsia. A gastrite tem diversos fatores etiológicos e pode ser classificada de acordo com sua evolução temporal, em aguda e crônica, mecanismo patogênico, localização anatômica e características histológicas.

A forma mais comum da gastrite crônica, que atinge predominantemente a região antral, tem como agente causador a bactéria HelicobacterPylori (H. Pylori) e está presente em até $100 \%$ em pessoas com 70 anos. Essa forma de gastrite aumenta com o decorrer do tempo e pode evoluir a uma pangrastrite, em média, num tempo de 15 a 20 anos.

Neste contexto clínico, pode-se ter atrofia gástrica com subsequente metaplasia, que poderá resultar em adenocarcinoma gástrico, sendo o H. Pylori considerado um fator de risco para câncer gástrico. Já a forma menos comum, conhecida como gastrite autoimune,surge devidoa presença de anticorpos contra as células parietais e fator intrínseco na vigência de anemia perniciosa, localizando-se no fundo do corpo gástrico (LONGO et al., 2014).

A infecção por $H$. Pylori induz a inflamação persistente na mucosa gástrica com diferentes tipos de lesões, por isso tem sido associado à etiopatogenia de diversas doenças, tais como úlcera péptica, câncer gástrico, MALT (linfoma do tecido linfoide associado a mucosa) e com o linfoma nãoHodgkin gástrico. Esta bactéria é o principal causador da gastrite, que é uma das infecções mais comuns na espécie humana, comprometendo cerca de metade da população mundial (GODOY et al. 2007; DDINE et al. 2012).

Segundo Caetanoet al. (2008), a endoscopia digestiva alta tem papel fundamental para definir o diagnóstico e o fator desencadeador de diversas doenças do trato gastrointestinal, e quando complementada com biópsias da mucosa gástrica constitui-se um método prevalente na detecção de H. pylori, no Brasil e no mundo.

Conforme Ladeira, et al. (2003), oHelicobacterpylori, é uma bactéria que vive 
no nosso estômago, podendo atingir o duodeno, sendo responsável pela mais comum infecção crônica em seres humanos. Esse microrganismo tem sido reconhecido em todas as populações do mundo e em indivíduos de todas as idades. Estimativas mais conservadoras sugerem que mais de $50 \%$ da população mundial possui o estômago colonizado por essa bactéria.

De acordo com Guimarães,et al. (2008), nos países sem saneamento básico universal, a maioria das crianças é infectada pelo $H$. pyloriantes dos 10 anos e a prevalência na população adulta chega a ser maior que $80 \%$. A presença do $H$. pylori é considerada fator associado (cofator) ao desenvolvimento de patologias gastrintestinais. Se esta patologia for tratada de forma adequada, os índices de erradicação ultrapassam $90 \%$.

Deve-se destacar que essa bactéria também está associada a risco de câncer de estômago (em $0,1 \%$ a $3 \%$ ) e linfoma do tipo MALT, doença maligna que se instala em cerca de um paciente para cada 10 mil infectados. (GUIMARÃES et al. 2008).

De acordo com Lopes (2013), o conceito de gastrite deve ser utilizado nos casos em que coexiste lesão celular, processo regenerativo e infiltração inflamatória, acrescidos da presença de folículos linfoides na mucosa gástrica, como também neutrófilos, plasmócitos, linfócitos e eosinófilos, de evolução aguda ou crônica, associado quase sempre à infecção por Helicobacterpylori.

Para os outros casos em que existe intenso dano celular à mucosa gástrica sem um processo inflamatório, denomina-se gastropatias. Geralmente as gastropatias resultam do uso indiscriminado de drogas anti-inflamatórias (AINEs), estresse, álcool, entre outros (LOPES, 2013).

Lopes (2013) descreveu que durante muito tempo soube-se da existência de uma bactéria de forma espiralada presente na mucosa gástrica, mas não tinha-se conhecimento de sua importância patológica.

Em 1983, Robin Warren e Barry Marshall realizaram um estudo que, através de biópsias gástricas de pacientes com gastrite crônica e úlcera péptica, conseguiram isolar a bactéria H. pylori (LOPES, 2013).

A partir de então, a correlação entre a infecção por esse microrganismo e gastrite crônica e úlcera péptica foi fundamental para que a bactéria fosse encarada como importante agente etiológico para essas doenças (LOPES, 2013).

Existem estimativas de que essa bactéria pode estar presente no estômago de aproximadamente metade da população mundial, entretanto, ainda é desconhecido por que essa bactéria é capaz de causar uma doença severa em certos hospedeiros e ser inofensivo em outros. 
Os achados clínicos são determinados por diversos fatores, como diferentes respostas do hospedeiro, fatores de virulência e influências ambientais ou a combinação desses fatores (VINAGRE, 2013).

Esta infecção está intimamente ligada à gastrite aguda e crônica, úlcera péptica e a adenocarcinoma, sendo reconhecidamente um agente carcinogênico tipo I. Também está intimamente ligada ao aparecimento de linfoma MALT, em que a maioria desses tumores pode ser curado somente com a erradicação da bactéria, (LIMA, 2014).

Parente, et al. (2010) estimaram que a infecção por $H$. pylori, uma das infecções mais prevalente em humanos,afete aproximadamente metade da população mundial em todos os continentes, sendo adquirida principalmente na infância. As taxas de prevalência são inversamente proporcionais a situação socioeconômica da população.

No Brasil, estudos indicam que as taxas de prevalência são muito elevadas, podendo chegar a taxas absurdas, tão elevadas quanto $86 \%$ e $97,9 \%$ em populações da região amazônica. Em estudo entre doadores de sangue assintomáticos na cidade de São Paulo, foi detectada uma prevalência de 65,3\%. Essa diferença possivelmente é reflexo da melhoria na qualidade de vida da população no estado mais desenvolvido do país (PARENTEet. al.; 2010).
A infecção por $H$. pylori está quase sempre relacionada a gastrite ativa crônica, podendo resultar em doença ulcerosa péptica, linfoma MALT e câncer gástrico, sendo resultado de uma complexa interação entre a bactéria e o hospedeiro. Sua mais importante característica de sobrevivência é a capacidade de colonizar a superfície do epitélio gástrico, abaixo da camada do muco (FAUCI, 2013).

Quanto aos fatores bacterianos, a $H$. pylori é capaz de facilitar sua fixação no estômago, induzir lesão da mucosa e se proteger da defesa do hospedeiro. Sua fixação é facilitada pela sua forma espiralada e possível pela ação da uréase, que hidrolisa a ureia presente na mucosa gástrica, produzindo amônia que tampona a acidez gástrica e pode danificar as células epiteliais.

A expressão de adesinas pela bactéria facilitam a fixação das mesmas às células epiteliais gástricas. Diferentes cepas produzem diferentes fatores de virulência, como Cag A, pic B e Vac a, que contribuem para patogenicidade, e juntamente com outros componentes bacterianos, causam danos na mucosa (FAUCI, 2013).

Do ponto de vista do hospedeiro, a resposta inflamatória ao patógeno inclui o recrutamento de neutrófilos, linfócitos, macrófagos e plasmócitos. Por se fixar às moléculas MHC de classe II, a bactéria produz uma lesão local induzida pela morte celular (apoptose). São encontradas elevadas 
concentrações de diversas citocinas no epitélio gástrico de indivíduos infectados pelo H. pylori, como interleucinas IL-1 $\alpha / \beta$, IL-2, IL-6, IL-9, fator de necrose tumoral $\alpha$ (TNF$\alpha)$ e internona (IFN- $\gamma)$, (FAUCI, 2013).

De forma geral, a infecção pelo Helicobacterpylori pode se manifestar de diferentes formas e apesar de geralmente ser assintomática é considerada um patógeno humano. Seu efeito final será determinado por fatores do microrganismo e do hospedeiro, como fatores de virulência e imunidade respectivamente. A presença de gastrite antral está associada a formação de úlcera duodenal; a gastrite do fundo e corpo gástrico ou pangastrite predispõe ao surgimento de úlceras gástricas, atrofia, linfoma MALT e adenocarcinoma (Figura 01) (SUERBAUM; MICHETTI et.al. 2002).

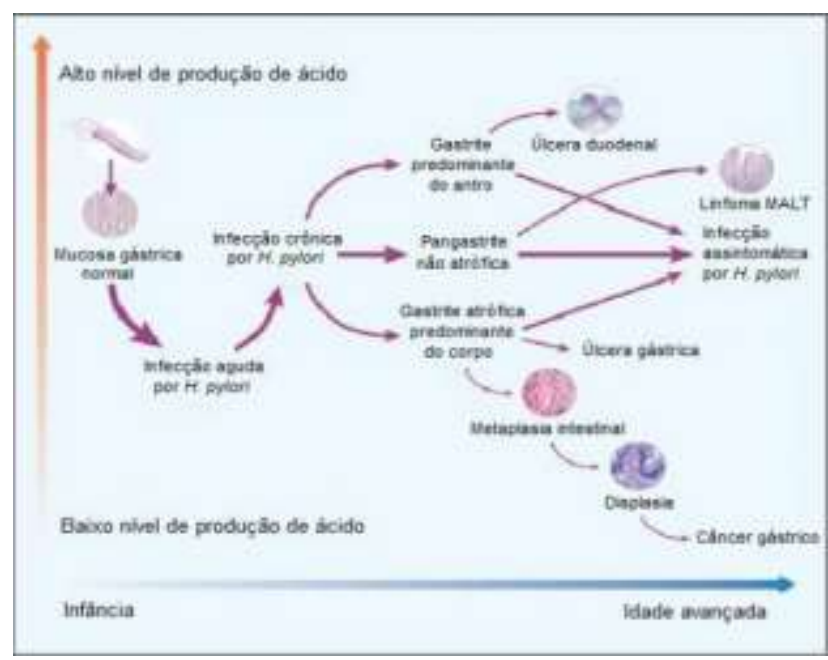

Figura 1 - História natural da infecção por Helicobacterpylori.

Fonte: Adaptado de Suerbaum e Michetti (2002).
De acordo com Lopes (2013), existem diversas formas de diagnóstico da presença de H. pylori na mucosa gástrica, podendo ser divididos basicamente em testes invasivos e não invasivos. Os testes invasivos são realizados durante a endoscopia, retirando fragmentos da mucosa, enquanto os não invasivos podem ser realizados pesquisando anticorpos anti-H. pylori.

Dentre os diagnósticos por meio endoscópico estão a histologia, cultura, uréase e PCR. A histologia é método confiável realizado a partir da coloração por marcadores de cortes histológicos retirados durante endoscopia. Recomenda-se a coleta de dois fragmentos do antro e dois do corpo gástrico para estudo. O uso prévio de antimicrobianos (nos últimos 30 dias) ou inibidores de bomba protônica (no últimos 7 a 10 dias) podem comprometer a acurácia do método.

A sensibilidade e especificidade do método são próximas a $95 \%$. Sendo um teste diagnóstico considerado padrão-ouro. Ométodo de cultura consiste em cultivar os fragmentos retirados endoscopicamente e a sua identificação é baseada na presença de colônias típicas, na morfologia ao Gram e da positividade para uréase e reações de oxidase e catalase. Esse método permite diagnóstico definitivo da infecção e realização do antibiograma, apresentando sensibilidade entre 82 a 92\% (LOPES, 2013). 
Sendo a $H$. pylori grande produtora da enzima urease, testes indiretos podem ser realizados na própria sala de endoscopia. Os fragmentos coletados são colocados em uma solução contendo ureia, que se colonizados pela $H$. pylori, por ação da urease, irão produzir amônia, elevando o pH da solução. Será utilizado um indicador, habitualmente vermelho de fenol, que se positivo irá alterar a cor do meio de amarelo para vermelho.

O uso de antagonistas dos receptores H2 da histamina, inibidores da bomba protônica, bismuto ou antimicrobianos irão afetar a acurácia do método. Possui sensibilidade superior a $90 \%$ e especificidade maior que 95\%. Estudos foram realizados para comparar os diferentes métodos de avaliação do material colhido por endoscopia para diagnóstico de infecção por $H$. pylori(LOPES, 2013).

Caetano et. al., 2008, realizaram estudo com 150 pacientes com queixas compatíveis com doenças pépticas, realizando endoscopias complementadas com biópsia da mucosa gástrica para teste histológico e urease, além da coleta de sangue para exame sorológico.

Não se observou diferença estatisticamente significante entre os métodos utilizados. Logo, pela facilidade do método, o trabalho concluiu que o teste de urease se credencia como método de escolha para aqueles que se beneficiarão com o diagnóstico endoscópico. Enquanto para os casos que a endoscopia não deva ou não possa ser realizada, indica-se a sorologia para diagnóstico da infecção.

Morillo, et al.(2011)compararam os valores de três testes diagnósticos (histopatológica com hematoxilina-eosina (HE), teste de urease e cultura microbiológica) baseados em fragmentos colhidos durante endoscopia. Observou-se diferenças significativas quando a avaliação histopatológica com H-E e o teste de urease foram comparas a cultura. Logo, os autores concluíram que com base em biópsias endoscópicas, a avaliação histopatológica com H-E e o teste de urease são os mais recomendados, mas destaca-se que a avaliação histopatológica é essencial quando exigido estudo de lesões gástricas. Ressalta que o teste de cultura é importante em casos que se faz necessária realização do antibiograma.

N0 Quadro1, observa-se que no Sistema Único de Saúde (SUS) nem todos exames diagnósticos estão presentes. $\mathrm{O}$ Projeto diretrizes realizado pelo CCATES (Centro Colaborador do SUS: Avaliação de Tecnologia e Excelência em Saúde), em Belo Horizonte, resume no Quadro 1, os métodos diagnósticos e suas respectivamente vantagens e desvantagens e disponibilidade no SUS. 
Estudos vem sendo realizados e está cada vez mais evidente que a erradicação do $H$. pylori tem ajudado a reduzir as chances de desenvolvimento de patologias gástricas mais graves, como o adenocarcinoma, que estão diretamente envolvidas com o microrganismo. Entretanto, a indicação de tratamento em algumas situações ainda permanece controversas (Tabela 1).

Tabela 1 -Helicobacterpylori e indicações para diagnóstico e tratamento.

\begin{tabular}{l|l}
\hline Estabelecidas & Controversas \\
\hline $\begin{array}{l}\text { Úlcera péptica ativa } \\
\text { (gástrica ou duodenal) }\end{array}$ & Dispepsia funcional \\
\hline $\begin{array}{l}\text { História prévia confirmada } \\
\text { de úlcera péptica (sem } \\
\text { tratamento prévio para H. } \\
\text { pylori) }\end{array}$ & Pólipos gástricos \\
\hline $\begin{array}{l}\text { Linfoma MALT gástrico de } \\
\text { baixo grau }\end{array}$ & DRGE \\
\hline $\begin{array}{l}\text { Após ressecção endoscópica } \\
\text { de câncer gástrico precoce }\end{array}$ & Usuários de AINE's \\
\hline \multirow{2}{*}{$\begin{array}{l}\text { Anemia ferropriva } \\
\text { de causa } \\
\text { desconhecida }\end{array}$} \\
\cline { 2 - 2 } & $\begin{array}{l}\text { Purpura } \\
\text { trombocitopênica } \\
\text { idiopática }\end{array}$ \\
\cline { 2 - 2 } & $\begin{array}{l}\text { Populações de alto } \\
\text { risco para câncer } \\
\text { gástrico }\end{array}$ \\
\hline
\end{tabular}

Fonte: Adaptado de Lopes(2013).

A erradicação definitiva do $H$. pylori é difícil de ser obtida, pois o microrganismo possui resistências primárias ou secundárias aos antimicrobianos, estando firmemente aderido ao epitélio gástrico e sendo possuidor de um glicocálice espesso.

Praticamente todos antimicrobianos disponíveis no mercado já foram testados contra o microrganismo, mas somente oito deles são hoje empregados no tratamento dessa infecção. São eles: Claritromicina, Amoxicilina, Sais de bismuto, Nitroimidazólicos, Tetraciclinas, Flurazolidona, Levofloxacina e Rifabutina não disponível no Brasil (LOPES, 2013).

De acordo com Lopes (2013), o tratamento para infecção dessa bactéria consiste na associação de inibidor de bomba protônica, amoxicilina e claritromicina duas vezes ao dia durante 7 dias, com índices de erradicação próximos a $85 \%$. Em alérgicos, a amoxicilina pode ser trocada por metronidazol. Caso haja falha terapêutica, empregar esquema quádruplo de sal de bismuto, tetraciclina, furazolidona e inibidor de bomba protônica, administrados 2 vezes ao dia durante 10 dias, ou associação de levofloxacina e inibidor de bomba protônica, associados à amoxicilina ou furazolidona, durante 10 dias. 
Quadro 1 - Exames diagnósticos para infecção por H. pylori, suas vantagens, desvantagens e disponibilidade no SUS.

\begin{tabular}{|c|c|c|c|}
\hline Teste endoscópico & Vantagens & Desvantagens & Disponibilidade no SUS \\
\hline Histológico & $\begin{array}{l}\text { Sensibilidade e especificidade } \\
\text { excelentes }\end{array}$ & $\begin{array}{l}\text { Requer infraestrutura e } \\
\text { pessoal treinado }\end{array}$ & Disponível \\
\hline Teste rápido de urease & $\begin{array}{l}\text { Excelente especificidade e } \\
\text { sensibilidade muito boa em } \\
\text { pacientes selecionados. É } \\
\text { rápido. }\end{array}$ & $\begin{array}{l}\text { Sensibilidade bastante } \\
\text { reduzida em pacientes já } \\
\text { tratados }\end{array}$ & Indisponivel \\
\hline Cultura & $\begin{array}{l}\text { Excelente especificidade. } \\
\text { Permite a condução de } \\
\text { antibiograma }\end{array}$ & $\begin{array}{l}\text { Difícil condução, pouco } \\
\text { disponível. Sensibilidade } \\
\text { marginal }\end{array}$ & Disponível \\
\hline $\begin{array}{c}\text { Reação em cadeia da } \\
\text { polimerase (PCR) }\end{array}$ & $\begin{array}{l}\text { Sensibilidade e especificidade } \\
\text { excelentes }\end{array}$ & $\begin{array}{l}\text { Método não padronizado } \\
\text { entre laboratórios, muito } \\
\text { pouco disponivel }\end{array}$ & Indisponivel \\
\hline Teste não endoscópico & Vantagens & Desvantagens & Disponibilidade no SUS \\
\hline $\begin{array}{l}\text { Testes de anticorpos } \\
\text { (quantitativo e qualitativo) }\end{array}$ & $\begin{array}{l}\text { Muito bom valor preditivo } \\
\text { negativo }\end{array}$ & $\begin{array}{l}\text { Valor preditivo positivo } \\
\text { depende da prevalência de } \\
\text { H. pylori do local. Não } \\
\text { recomendado pós- } \\
\text { tratamento }\end{array}$ & Disponível \\
\hline $\begin{array}{c}\text { Teste respiratório com ureia } \\
\text { marcada com } C^{13} \text { (teste do } \\
\text { sopro) }\end{array}$ & $\begin{array}{l}\text { Identifica infecção ativa. Valor } \\
\text { preditivo positivo e valor } \\
\text { preditivo negativo excelentes, } \\
\text { independente da prevalência } \\
\text { de H. pylori. Útil antes e após } \\
\text { o tratamento }\end{array}$ & Pouco disponivel & Indisponivel \\
\hline Teste de antígeno nas fezes & $\begin{array}{l}\text { Identifica infecção ativa. Valor } \\
\text { preditivo positivo e valor } \\
\text { preditivo negativo excelentes, } \\
\text { independente da prevalência } \\
\text { de H. pylori. Útil antes e após } \\
\text { o tratamento }\end{array}$ & $\begin{array}{l}\text { Teste policlonal menos } \\
\text { validado em comparação ao } \\
\text { teste respiratório com ureia } \\
\text { marcada. Teste monocional } \\
\text { parece confiável antes e após } \\
\text { n tratamento }\end{array}$ & Indisponivel \\
\hline
\end{tabular}

Fonte: CCATES. Diretrizes para diagnósticoe erradicação do H. pylori utilizandomedicamentos da Atenção Primária (SUS), 2014.

Visto a relevância do diagnóstico dessas doenças e do agente causador para a população portadora de H. pylori, o objetivo deste estudo consistiu em fazer um levantamento de dados a partir de registros do SAME do Hospital Universitário Alzira Vellano (HUAV) na cidade de Alfenas, MG.

Em seguida, após identificar a presença da infecção pelo Helicobacterpylori, verificou-se a relação deste tipo de infecção com a gastrite crônica, em pacientes que passaram pelo serviço de endoscopia digestiva alta e biópsia do estomago, realizados no HUAV.

\section{Metodologia}

Foi conduzido um estudo transversal de base secundária, através do levantamento de dados disponíveis em laudos patológicos de pacientes que foram submetidos as biopsias realizadas por endoscopia digestiva alta registradosno Hospital Universitário Alzira Velano, Alfenas - MG, durante o 
período de 2009 a 2014. Foram analisados 753 registros médicos.

Após a coleta das informações,foi utilizado o teste estatístico exato de Fisher, ao nível nominal de significância de 5\%.

Numa primeira etapa, as hipóteses testadas foram:A gastrite independe da variável $x$, sendo $x, H$. pylori ou gênero?

$\mathrm{N}$ segunda etapa, a hipótese testada foi:A infecção pelo $H$. pylori independe dogênero?

As análises foram realizadas no software estatístico R ( $\mathrm{R}$ CORE TEAM, 2016).

\section{Resultados e Discussão}

Os resultados apresentados na Tabela 2 permitem concluir que houve uma dependência entre gastrite e o gênero $(\mathrm{p}=0,0339)$.

Verificou-se que prevalência de $H$. pylorientre o sexo feminino foi 1,4 vezes maior se comparado ao sexo masculino (resultados não apresentados).

Não foi observado uma relação entre gastrite e H. pylori, ( $\mathrm{p}=0,3246)$. Além disso, a associação entre $H$. pylorie o gênero não foi significativa, $(\mathrm{p}=0,5846)$.

Estes resultados foram contrários aos obtidos por Lima (2014), em que observou que esta infecção está intimamente ligada à gastrite aguda e crônica, úlcera péptica e a adenocarcinoma, sendo reconhecidamente um agente carcinogênico tipo I.

Tabela 2. Teste de independência ao nível de $5 \%$ de significância para as hipóteses testadas previamente definidas.

\begin{tabular}{l|l}
\hline Relações & p-valor \\
\hline Gastrite vsH. pylori & $0,3246 n s$ \\
Gastrite vsgênero & $0,0339^{*}$ \\
H. pylorivsgênero & $0,5846 \mathrm{~ns}$ \\
\hline
\end{tabular}

*Significativo ao nível nominal de 5\% de significância, $(\mathrm{p}<0,05)$.

${ }^{\text {ns }}$ Não significativo, $(\mathrm{p}>0,05)$.

Fonte: Dados da pesquisa

Na Figura 2 pode-se observar através das frequências percentuais que a faixa etária em que houve maior prevalência de $H$. pylori foi de 50 a 59 anos, totalizando aproximadamente, $24 \%$. Em seguida, verificase que as faixas etárias de 20 a 29 anos e, 40 a 49 anos, apresentaram prevalência de $H$. pyloride $18,3 \%$, respectivamente.

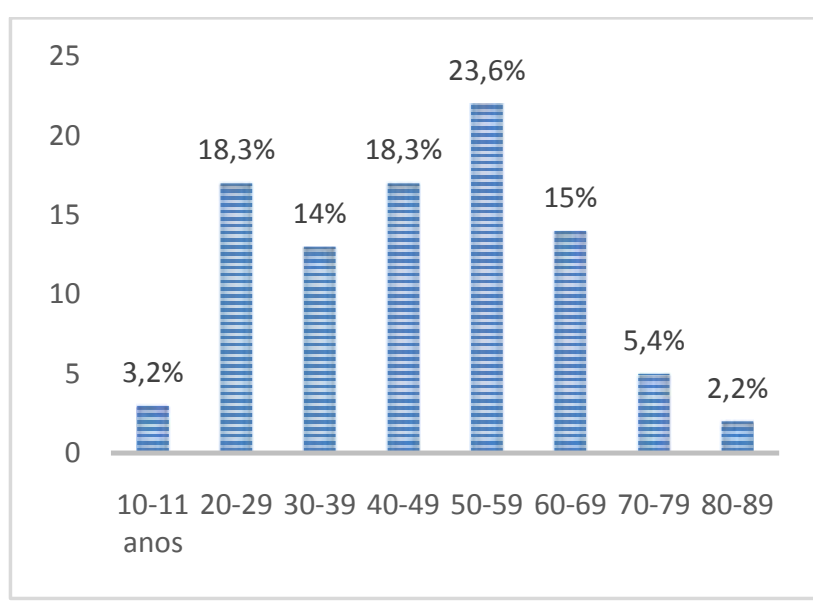

Figura 2. Prevalência de $H$. pylori na presença de gastrite acordo com as faixas etárias dos participantes. Fonte: Dados da pesquisa

Observa-se que apenas $5,4 \%$ dos participantes, com idade entre 70 e 79 anos, apresentaram H. pylori, (FIGURA 1). 
Esta baixa frequência observada não corrobora com os resultados obtidos por Longo, et al. (2014). Os autores verificaram que $100 \%$ dos participantes com $H$. pylori possuíam 70 anos de idade.

\section{Conclusão}

Os resultados permitem concluir que houve associação significativa entre a gastrite e o gênero, porém, não foi observado uma associação significativa entre a gastrite e $H$. Pylori.

\section{Referências Bibliográficas}

CAETANO, A. et al. Helicobacterpylori e doença péptica: estudo comparativo de métodos diagnósticos. Arq. Gastroenterol. São Paulo, v. 45, n. 3, p. 255-257, Set. 2008. Disponível em:

http://www.scielo.br/scielo.php?script=sci_art text\&pid=S000428032008000300018\&lng=en\&nrm=iso.

Acessado em 29 Set 2015.

CCATES. Diretrizes para diagnóstico e erradicação do $H$. pylori utilizando medicamentos da Atenção Primária (SUS), 2014. Belo Horizonte. Disponível em http://www.ccates.org.br/content/_pdf/PUB_1 405104160.pdf. Acessadoem 30 Set 2015.

DDINE, L. C. et al. Factors associated with chronic gastritis in patients with presence and absence of Helicobacter pylori.ABCD, arq.bras. cir. dig. [online], vol.25, n.2, pp. 96100. ISSN 0102-6720, 2012. Disponível em: http://dx.doi.org/10.1590/S010267202012000200007.

FAUCI, A. S., et al. HARRISON -

Medicina Interna. Vol.2, $17^{\mathrm{a}}$ edição. Rio de
Janeiro: McGraw-Hill Interamericana Brasil, 2008.

FERREIRA,D.F. Estatística Básica.Lavras: Editora UFLA,2009, 2a ed. rev. 664p.

FEDERAÇÃO BRASILEIRA DE GASTROENTEROLOGIA. Condutas em Gastroenterologia - FBG. Rio de Janeiro: Editora Revinter, $1^{\mathrm{a}}$ edição, 2004.

GODOY, A.P.O. et al. Análise das impressões digitais de DNA e de fatores de virulência de linhagens de Helicobacterpylori. Arq. Gastroenterol. [online], vol.44, n.2, pp. 107-112. ISSN 16784219, 2007,Disponível em: http://dx.doi.org/10.1590/S000428032007000200004.

GUIMARÃES, J.; CORVELO, T. C.; BARILE, K.A. Helicobacterpylori: fatores relacionados à sua patogênese. Revista Paraense de Medicina, Belém-PA, 2008. LADEIRA, M. S. P.; SALVADORI, D. M. F.; RODRIGUES, M. A. M. Biopatologia doHelicobacterpylori. Rio de Janeiro-RJ: Jornal Brasileiro de Patologia e Medicina Laboratorial, 2003.

LIMA, K.S. et al. Helicobacter pylori and $\mathbf{t}(11 ; 18)(q 21 ; q 21)$ translocation in gastric MALT lymphoma.Arq. Gastroenterol. São Paulo, v. 51, n.2, p.84-89, Junho, 2014.

Disponível em:

http://www.scielo.br/scielo.php?script=sci_art text\&pid=S0004$28032014000200084 \& \operatorname{lng}=$ en \&nrm=iso. Acessado em 29 Set 2015.

LONGO, D. L., et al. Gastrenterologia e Hepatologia de Harrison. $2^{\circ}$ edição. Rio de Janeiro: Editora Mc Graw-Hill, 2014.

LOPES, A. C. Clínica Médica: Diagnóstico e Tratamento. Editora Atheneu, vol.2. São Paulo, 2013.

MORILLO, A. G., et al. Comparison of three methods based on endoscopic gastric 
biopsies for diagnosis of Helicobacter pylori active infection in a clinical setting. Arq. Gastroenterol. São Paulo, v. 48, n. 3, p. 190194, Sept. 2011. Disponível em:

http://www.scielo.br/scielo.php?script=sci_art text\&pid=S0004$28032011000300007 \& \operatorname{lng}=$ en $\& n r m=$ iso.

Acessado em 29 Set 2015.

PARENTE, J. M. L.; PARENTE, M. P. P. D.

$P$. Contexto epidemiológico atual da infecção por Helicobacterpylori.

GastroenterolEndosc Dig.v.29, n.3, p.86-89, 2010.

R CORE TEAM.R: A language and environment for statistical computing. $R$ Foundation for Statistical Computing, Vienna. 2016.

SUERBAUM, S.; MICHETTI, P. Medical Progress: Helicobacter pylori Infection.The New England Journal of Medicine.v.347, n.15, Octob, p.1175-1186, 2002.

VINAGRE, R. M. D. F., et al. Role of Helicobacter Pylori infection and lifestyle habits in the development of gastroduodenal diseases in a population from the Brazilian Amazon.Arq.Gastroenterol. São Paulo, v. 50,n. 3, p.170-174, Set. 2013. Disponível em: http://www.scielo.br/scielo.php?script=sci_art text\&pid=S000428032013000300170\&lng=en\&nrm=iso. Acessado 29 Set 2015. 